Continuous and categorical data were summarised as median with interquartile ranges and proportions respectively. Continuous variables were compared with Mann Whitney rank-Sum test and categorical variables by Fisher exact test. Statistical significance was taken as $\mathrm{p}<0.05$ for all tests.

Results Twenty seven admissions were identified. The median age was 8 (5-18) months. Respiratory syncytial virus (37\%) was the most common virus isolated.

Fourteen (52\%) patients have CHD. There was no difference in proportion of children with DS and CHD requiring high dependency care (HD) compared to those without. (4/14 vs. 2/ $13, p=0.648)$. There was no difference in proportion of those with DS and CHD requiring intensive care (ICU) and those without $(1 / 14$ vs. $1 / 13, \mathrm{p}=0.999)$. There was no difference in median LOS between those with CHD and those without. (6.5 vs. 7 days, $\mathrm{p}=0.678)$. After excluding those CHD with corrective surgery done, there is still no significant difference between the two groups.

Conclusion We did not find any association between CHD and increase in morbidity among children with DS admitted for bronchiolitis.

\section{PS-361 EVALUATING PARENT SATISFACTION WITH MEDICAL CORRESPONDENCE FOLLOW UP METHODS AFTER A CARDIOLOGY OUTPATIENT CLINIC VISIT IN OUR LADY'S CHILDREN HOSPITAL, IRELAND}

${ }^{1} \mathrm{M}$ Bahari, ${ }^{2} \mathrm{~K}$ Walsh, ${ }^{3} \mathrm{D}$ McGill. 'Neonatology, National Maternity Hospital, Dublin, Ireland; ${ }^{2}$ Cardiology, Our Lady's Children Hospital, Dublin, Ireland; ${ }^{3}$ Department of Public Health and Policy, University of Liverpool, Liverpool, UK

\subsection{6/archdischild-2014-307384.660}

Background and aim Primary: To evaluate parents' satisfaction toward being copied into their GP letters after Paediatric Cardiology outpatient visits. Secondary: To explore acceptance of other methods of communication, and factors affecting acceptance.

Methods This was a quantitative, descriptive, cross sectional study assuming a positivistic approach. Questionnaires filled by participants were used to collect data in Cardiology Outpatient. September 10th to October 17th, 2009. Patients attending during the specified period were included; new referrals were excluded. A representative sample was calculated at 55 participants. 87 agreed to participate but only 66 returned questionnaire. Data was imported and analysed using PASW 18.

Results 97\% of Participants were satisfied when copied into GP letter. Parents discussion with a Paediatrician was the most helpful followed by GP, nurse, family member and other parents, with similar experience. Paediatrician was first choice for parents to discuss their children's health followed by GP, nurse, and other Parents. 60\% of Participants found the internet to be a helpful source for information, and 51\% found Patient Education Material (PED) helpful. Despite this Parents prefer PED to Internet. 94\% of Participants want to receive a copy of Paediatrician letter, but were divided over other methods of communication. Receiving a letter contributes significantly to parents' satisfaction $(\mathrm{p}=0.008)$. Gender and level of education was shown to influence participants' choice of communication.

Conclusion Parents hold high regards for being part of communication between health professionals. The use of medical terms does not render the usefulness of the letter to parents.

\section{PS-362 EPIDEMIOLOGY OF OROFACIAL CLEFTS IN EMILIA ROMAGNA AND TUSCANY REGIONS}

${ }^{1} \mathrm{M}$ Rubini, ${ }^{2} \mathrm{~S}$ Franchella, ${ }^{1} \mathrm{G}$ Astolfi, ${ }^{3} \mathrm{~F}$ Bianchi, ${ }^{1} \mathrm{P}$ Franceschelli, ${ }^{3} \mathrm{~A}$ Pierini, ${ }^{1} \mathrm{D}$ Balestra, ${ }^{4}$ A Franchella. ${ }^{1}$ Emilia Romagna Region, Imer, Ferrara, Italy; ${ }^{2}$ University Hospital, Otosurgery Unit, Padua, Italy; ${ }^{3}$ Tuscany Region, Malformations Register, Florence, Italy; ${ }^{4}$ Maternity and Childhood, Pediatric Surgery, Ferrara, Italy

\subsection{6/archdischild-2014-307384.661}

Background and aim Epidemiological information gathered through Birth defects surveillance is an important adjunct to carrying out clinical and etiological research.

Methods An Italian epidemiological investigation on Orofacialclefts (OFCs) conducted by the Congenital Malformation Registries of Emilia/Romagna (http://www.registroimer.it/) and Tuscany (http://www.rtdc.it/) in the period 2001-2011 identified 751 of OFC cases among 724.944 with an overall birth prevalence of 1.04/1,000. Birth prevalence of OFC variessignificantly in Europe ranging from 6,2 to 22,9 with a European mean value of1,45, showing a clear difference between the north and south of Europe (http://www.eurocat-network.eu/). The complex model of inheritance and the frequently conflicting results in different populations on the role of genes that constitute risk factors, suggest the presence of real biological differences.

Results Recorded cases included 166 (22\%) CL, 286 (38\%) CLP and 299 (40\%) CP. A predominance of males among CL (P) (M/ $\mathrm{F} 1,60)$ and of females among $\mathrm{CP}(\mathrm{M} / \mathrm{F} 0,79)$ as confirmed. Among 751 of OFC cases, 661 were live births (88.0\%), 7 stillbirths $(0.9 \%)$, while $83(11.1 \%)$ were terminations of pregnancy.522 cases (69\%) were isolated, 118 cases (16\%) OFC were present in recognised condition, and 111 cases $(15 \%)$ were associated with other congenital malformations (MCA). The study confirmed that cardiovascular (27\%), musculoskeletal (21\%) and central nervous system (21\%) defects are frequently associated.

Conclusions Thus a routine screening for other malformations may need to be considered in infants with OFC and a multidisciplinary approach of these patients to be organised starting from birth.

\section{PS-363 ACUTE PAEDIATRIC ADMISSION UNITS (APAU) CAN REDUCE OVERALL ADMISSIONS AND IMPROVE QUALITY OF CARE IN A DISTRICT GENERAL HOSPITAL (DGH) SETTING}

${ }^{1} \mathrm{G}$ McCall, ${ }^{2} \mathrm{NP}$ Corrigan. ${ }^{1}$ Paediatrics, Antrim Hospital, Belfast, UK; ${ }^{2}$ Paediatrics, Altnagelvin Hospital, Derry, UK

\subsection{6/archdischild-2014-307384.662}

Despite UK wide enthusiasm for Acute Paediatric Admission Units the wide variation in unit size and configuration makes generalisation of impact difficult. We believed that introducing an APAU in a DGH setting had the potential to reduce admissions, improve quality of patient care and help met $\mathrm{RCPCH}$ quality outcomes.

Aim To design, implement and audit an APAU with a defined patient pathway for all acute referrals. Primary outcomes would include admission rates, time to assessment, time to decision and questionnaires.

Method Retrospective data was collected to provide a baseline against which to judge efficacy of intervention. A designated area was identified and equipped as an APAU. Patient pathways were agreed along with a new admission proforma. A 4-week 
pilot was carried out from 8 am- 8 pm Monday to Friday. Data collected included time of arrival and assessment, admission rates, parental and staff satisfaction.

Results During Jan 2013 and April 2013 between 8 am-8 pm there was a total of 785 admissions. A retrospective analysis was carried out on 80 randomly selected charts. Ages ranged from 3 weeks to 13 years 9 months, with a median age of 3 years 5 months. $97 \%$ of patients were seen within $4 \mathrm{~h}$ of nursing triage with only $59 \%$ being reviewed by a senior doctor within the following $4 \mathrm{~h}$ of their initial medical review.

There were 100 APAU admissions during May 2013. Only 87 charts were available and audited. Ages ranged from 2 days to 14 years with a median age of 1 year 7 months. Common diagnoses included gastroenteritis and respiratory tract infections. $100 \%$ of patients were medically assessed within $4 \mathrm{~h}$ of nursing triage with $85 \%$ of patients being reviewed by a senior doctor within the following $4 \mathrm{~h}$ ( $\mathrm{p}$ value 0.01 ).

Admission rates fell from $95 \%$ to $44 \%$ during the hours of 8 am-8 pm ( $\mathrm{p}$ value $<0.0001)$. Staff impression of our facilities for managing direct admissions as good or excellent improved from $25 \%$ to $95 \%$. Patient and parent feedback was excellent.

Conclusion We have shown that developing a model of acute paediatric assessment in a DGH setting can both reduce admissions and improve quality outcomes. Both physical infrastructure and funding remain issues for sustainability however we believe that this project demonstrates the value in investing in acute paediatric care.

\section{Primary Care: Infections}

\section{PS-364 RELATIONSHIP BETWEEN SMOKING PARENTS AND HOSPITAL LENGTH OF STAY IN ACUTE BRONCHIOLITIS}

${ }^{1} \mathrm{JC}$ Flores-Gonzalez, ${ }^{1}$ B Serrano-Moyano, ${ }^{2} \mathrm{AM}$ Lechuga-Sancho, ${ }^{1} \mathrm{~L}$ Garcia-Garcia, ${ }^{1} \mathrm{FJ}$ Dávila-Corrales, ${ }^{1} \mathrm{JJ}$ Perez-Guerrero, ${ }^{1} \mathrm{MA}$ Matamala-Morillo, ${ }^{1} \mathrm{RM}$ Garcia-Ortega, ${ }^{1} \mathrm{P}$ Rodriguez-Campoy, ${ }^{1}$ E Palma-Zambrana, ${ }^{1} \mathrm{P}$ Comino-Vazquez. ${ }^{1}$ Pediatrics Department, Hospital Universitario Puerta Del Mar, Cádiz, Spain; ${ }^{2}$ Cadiz University, Hospital Universitario Puerta Del Mar, Cádiz, Spain

\subsection{6/archdischild-2014-307384.663}

Background and aims The smoking parent is considered a risk factor of severity for acute bronchiolitis (AB). We aimend to evaluate the relationship between parental history of smoking and length of stay of infants hospitalised for AB.

Methods Prospective descriptive study including all infants admitted for moderately bronchiolitis, between 2011 and 2013 . They were grouped in smoking parent or not. Severe bronchiolitis and patients with serious risk factors were excluded. The primary outcome was length of stay (LOS). The following variables were recorded: age, sex, atopic dermatitis, parental atopy, number of siblings, breastfeeding, RSV, treatment received, need for PICU, mortality and clinical score at admission.

Results Among the 137 enrolled infants, 56.2\% had no smoking parent. There were no statistically significant differences $(p>0.05)$ between the two groups in the following variables: median age (40 vs 59 days), male gender (48\% vs 53\%), atopic dermatitis $(6.7 \%$ vs $15.6 \%)$, breastfeeding (59.7\% vs $53.3 \%)$, number of siblings ( 0.66 vs. 0.63$)$ day care attendance $(16.9 \%$ vs. $6.7 \%)$, severity score (5.35 vs 5.28 ), percentage of positive RSV (67\% vs 65\%) and PICU admission (7.8\% vs 5\%). There were statistically significant differences in parental atopy $(\mathrm{p}=$
0.04). The median LOS in the smoking parent group was 3.33 days compared with 3.11 days in the other group ( $p=0.239$ ). Conclusions There are no significant differences in mean hospital stay among patients with moderate $\mathrm{AB}$ with or without a history of smoking parent. In our series smoking parent is not a severity risk factor for $\mathrm{AB}$.

\section{PS-365 VALIDATION OF A CLINICAL SCALE IN ACUTE BRONCHIOLITIS}

${ }^{1} \mathrm{JC}$ Flores-Gonzalez, ${ }^{1}$ B Serrano-Moyano, ${ }^{2} \mathrm{G}$ Jimenez-Gómez, ${ }^{3} \mathrm{AM}$ Lechuga-Sancho, ${ }^{1} \mathrm{~L}$ Garcia-Garcia, ${ }^{1} \mathrm{FJ}$ Dávila-Corrales, ${ }^{1} \mathrm{JJ}$ Perez-Guerrero, ${ }^{1} \mathrm{E}$ Palma-Zambrana, ${ }^{1} \mathrm{P}$ Comino-Vazquez, 'MA Matamala-Morillo, 'P Rodriguez-Campoy, 'RM Garcia-Ortega. 'Pediatrics Department, Hospital Universitario Puerta Del Mar, Cádiz, Spain; ${ }^{2}$ Research Unit, Hospital Universitario Puerta Del Mar, Cádiz, Spain; ${ }^{3}$ Cadiz University, Hospital Universitario Puerta Del Mar, Cádiz, Spain

\subsection{6/archdischild-2014-307384.664}

Background and aims Most of clinical scales used in the assessment of acute bronchiolitis are not validated or are partial validated. The objective of this study is the validation of a clinical scale in the assessment of acute bronchiolitis (AB).

Material and methods Validation of a clinical severity scale in the context of a randomised, double-blind, clinical trial. 148 infants hospitalised with moderate acute bronchiolitis for 2 epidemics (2011-2013) were included. Demographics and clinical data were recorded. Different observers assessed all patients at admission and three times daily until discharge with WoodDownes modifies by Ferres (WDF) scale. Mild bronchiolitis and those with severity risk factors were excluded. The primary outcome was the difference in the numeric rating scale since admission until were discharged from hospital or admitted to PICU. The collected variables were analysed using non-parametric tests. In all cases it was considered a significance level of 95\%.

Results Mean age and range interquartílico [IQR] 1.5 months (1-3), 50\% were male. The WDF scale in patients admitted to PICU was significantly higher $(6(4-8)$ vs $5(4-8), \mathrm{p}=0.026)$. The WDF scale decreased an average of 3.87 points $(95 \% \mathrm{CI}$, 2.5-6.5) from admission to the time of discharge.

Conclusions Our results suggest that the WDF scale is related to the severity and outcome of patients with acute bronchiolitis at admission and at discharge. It's change from admission to discharge, which show a clear decrease adequately, reflect good clinical evolution necessary for discharge home.

\section{PS-366 ASSOCIATION OF TACHYCARDIA WITH SERIOUS BACTERIAL ILLNESS IN YOUNG CHILDREN AND ITS COMPARISON WITH RAISED C-REACTIVE PROTEIN AND WHITE CELL COUNT (WCC): OBSERVATIONAL STUDY}

1 J Abbasi, ${ }^{2}$ V Allgar, ${ }^{3}$ I Thopte. ${ }^{1}$ Paediatrics, York District Hospitals NHS Trust, York, UK; ${ }^{2}$ Medicine, Hull York Medical School, York, UK; ${ }^{3}$ Paediatrics, York District Hospital NHS Trust, York, UK

\subsection{6/archdischild-2014-307384.665}

Background and aims Diagnosis of serious bacterial illness (SBI) in children can be challenging despite it being endemic. Few studies have looked at clinical features and investigations in diagnosis of SBI. We compared tachycardia with C-reactive protein (CRP) and WCC to establish which is better for predicting SBI.

Methods Prospective cohort study of children $<6$ yrs referred to an acute assessment unit with febrile illness (July 2012-March 